\title{
Light-Load Efficiency Improvement Using Load Adaptive Gate Driving Method
}

\author{
Jae-Hyun Kim, Jae-Bum Lee, Jong-Woo Kim, \\ Gun-Woo Moon \\ Department of Electrical Engineering \\ Korea Advanced Institute of Science and Technology \\ Daejeon, Republic of Korea
}

\author{
Jae-Kuk Kim \\ Samsung Electro-Mechanics \\ Suwon, Republic of Korea
}

\begin{abstract}
In this paper, a new gate driving method to improve light-load efficiency is proposed for the power conversion system with a standby converter. The proposed method reduces the gate driving voltage of power MOSFETs and operating voltage of controller ICs under light load conditions by adjusting the auxiliary output voltage of the standby converter. Therefore, the gate driving loss on MOSFETs and the loss on controller ICs are significantly reduced without the degradation of performance in the main power stage. To confirm the validity of this study, the DC/DC server power supply with $48 \mathrm{~V}$ input, $12 \mathrm{~V} / 60 \mathrm{~A}$ output for the $\mathrm{DC} / \mathrm{DC}$ stage, and $5 \mathrm{~V} / 3 \mathrm{~A}$ output for the standby stage is experimented.
\end{abstract}

Index Terms - Gate driving method, light load efficiency, server power supply, standby converter

\section{INTRODUCTION}

Today, energy saving in power supplies is an essential issue in order to suppress global warming. As consumer electronic devices and data-processing equipment have grown rapidly, this environmental concern has prompted manufacturers to minimize power consumption under light load conditions as well as full load condition. For example, the 80 Plus incentive program [1] and Climate Saver Computing Initiative (CSCI) [2] require high efficiency from full load to $10 \%$ load condition. Furthermore, many manufacturers for computer, telecom, and network equipment require high efficiency under light load conditions that exceed the latest Energy Star specifications, and these requirements tend to be extended down to even $5 \%$ load. Thus, many literatures have been presented to improve the light load efficiency [3]-[26].

Generally, the power converters degrade the conversion efficiency mainly due to the conduction loss on semiconductor devices under heavy load conditions. On the other hand, power consumption under light load conditions is dominated by the switching loss and the gate driving loss on semiconductor devices, the power loss on controller ICs, and the core loss on magnetic components [7]-[9]. Among many methods to improve light-load efficiency, decreasing switching frequency is widely used by using the variable frequency control [10], [11] and burst mode control [9], [12], which reduces the

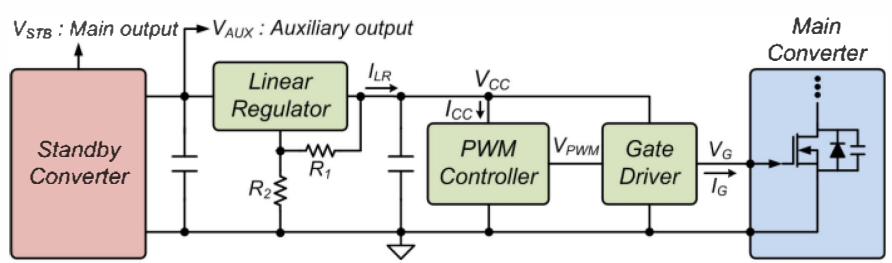

Fig. 1. Typical gate driving circuit in the power supply

switching loss and gate driving loss. However, they lead to poor dynamic performance because the operating frequency changes over a wide range according to the load variation, and in case of the burst mode operation, poor electromagnetic interference (EMI) and audible noise are other issues [8]. On the other hand, reducing gate driving loss can be an effective method to improve light-load efficiency without the degradation of performance in the main power stage [13]-[26].

Fig. 1 describes the typical gate driving circuit in the power supply with the standby converter. In general, the standby converter provides operating power for controller ICs and gate drivers by using auxiliary output stages. The linear regulator tightly regulates the voltage $V_{C C}$ from the auxiliary output voltage $V_{A U X}$. Meanwhile, the gate driving loss can be reduced by modifying the main power stage, which means that one power MOSFET with large gate charge is replaced by paralleled several MOSFETs with small gate charge, and some of them are turned off under light load conditions so that total gate charge can be decreased [13]-[15]. However, these methods are suitable for the integrated power stage, but not for the discrete power stage due to the large size of many discrete MOSFETs. Other techniques, the resonant gate driver (RGD) circuit [16]-[22] and adaptive gate driving voltage methods [23]-[25], modify the gate driver circuit. The resonant gate drive circuit can recycle the gate charge by using LC-resonance, and the adaptive gate driving voltage methods can reduce the gate charge by decreasing the gate driving voltage $V_{G}$ of the gate driver, which results in low power consumption on the gate driver. However, these methods are complex, and especially RGD circuit has a large inductor when the converter operates at low switching frequency. Meanwhile, there is another method 


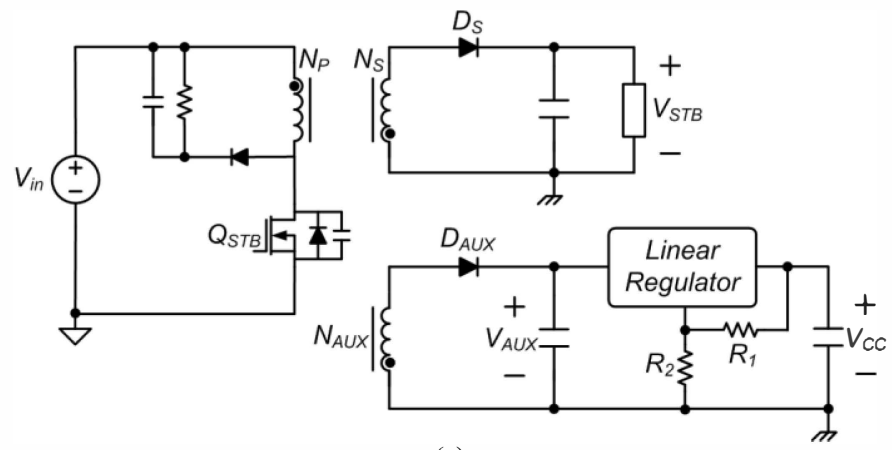

(a)

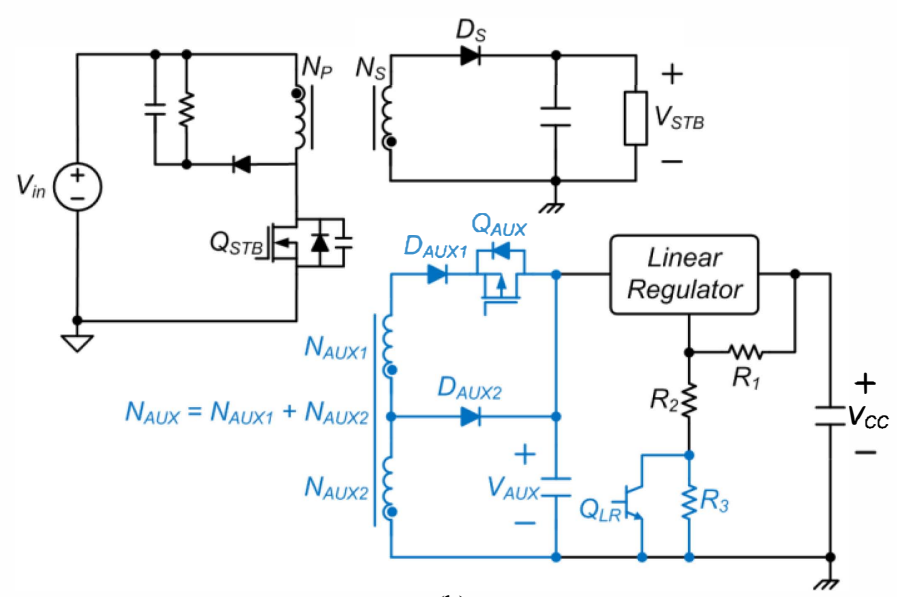

(b)

Fig. 2. Standby converter (a) conventional structure (b) proposed structure

to modify the linear regulator circuit in [26], where $V_{C C}$ of linear regulator becomes decreased to reduce $V_{G}$ under light load conditions. However, it has the adverse effect that the reduced $V_{C C}$ makes large loss on the linear regulator.

This paper presents a simple method to reduce power loss under light load conditions for the power supply with the standby converter. The proposed method can decrease not only $V_{C C}$ but also $V_{A U X}$ in the standby converter under light load conditions so that the gate driving loss as well as the loss on the controller ICs and linear regulator circuit can be reduced significantly.

\section{PROPOSED METHOD}

The proposed method is based on a simple observation that the gate driving loss $P_{G}$, the controller loss $P_{C O N}$, and the loss on linear regulator $P_{L R}$ are related to $V_{A U X}$ and $V_{C C}$ in Fig. 1. Those losses are given by

$$
\begin{aligned}
& P_{G}=Q_{G} V_{G} f_{s}=Q_{G} V_{C C} f_{s}=C_{i s s} V_{C C}^{2} f_{s} \\
& P_{C O N}=V_{C C} I_{C C} \\
& P_{L R}=\left(V_{A U X}-V_{C C}\right) I_{L R},
\end{aligned}
$$

where $Q_{G}$ is the gate charge of the MOSFET, $C_{i s s}$ is the input capacitance of the MOSFET, $f_{S}$ is the switching frequency, $I_{C C}$ is the current on the controller, $I_{L R}$ is the current on the linear regulator. Typically, $V_{G}=V_{C C}$. It is clear from (1) and (2) that decreasing $V_{C C}$ can reduce $P_{G}$ and $P_{C O N}$. Meanwhile, since low gate driving voltage indicates low gate charge and low current

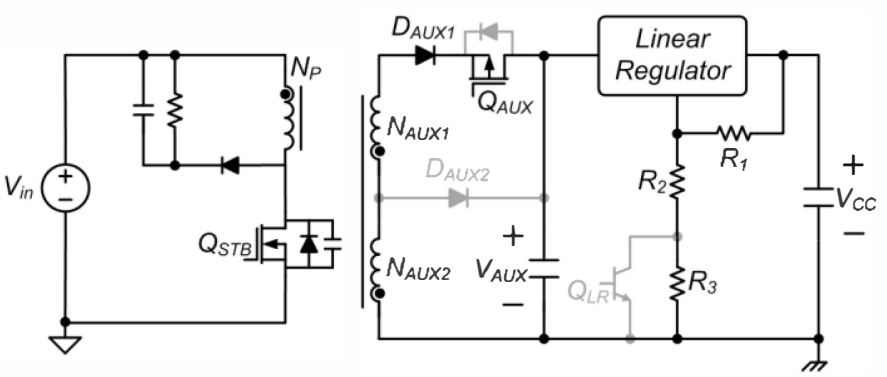

(a)
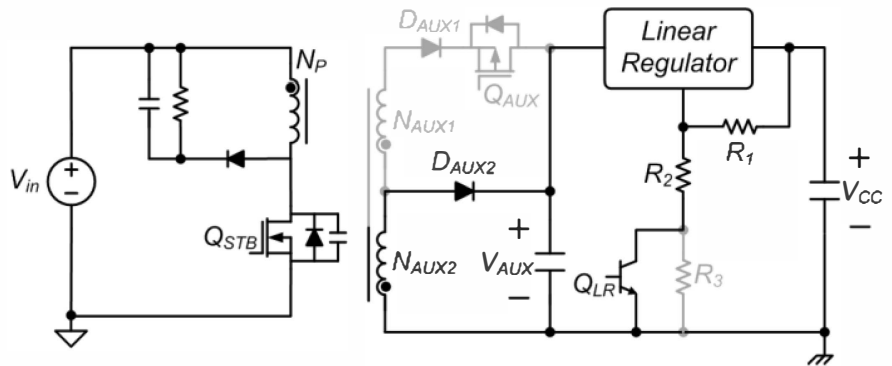

(b)

Fig. 3. Operational principle of the proposed standby converter under (a) heavy load conditions (b) light load conditions

$I_{G}$ flowing toward the gate node of the MOSFET, $I_{L R}$ can be reduced by decreasing $V_{C C}$, which results in low $P_{L R}$. However, we can know from (3) that it is undesirable to reduce $V_{C C}$ only in the linear regulator circuit as $P_{L R}$ increases. On the other hand, if not only $V_{C C}$ but also $V_{A U X}$ decreases in the linear regulator circuit, $P_{L R}$ can be reduced due to decreased $I_{L R}$. Therefore, in the proposed method, both $V_{A U X}$ and $V_{C C}$ become low level under light load conditions so that $P_{G}, P_{C O N}$ and $P_{L R}$ can be reduced greatly.

The implementation of the proposed method is described in Fig. 2. Generally, the multi-output flyback converter in Fig. 2(a) is widely used for the standby converter due to a simple structure and low cost. The primary switch $Q_{S T B}$ controls the main output voltage $V_{S T B}$ through the main secondary winding $N_{S}$ and diode $D_{S}$, whereas $V_{A U X}$ is cross-regulated through the auxiliary winding $N_{A U X}$ and diode $D_{A U X}$. As the cross-regulation characteristic is poor in the flyback converter, the linear regulator is used to tightly regulate $V_{C C}$ from $V_{A U X}$. On the other hand, in order to reduce both $V_{A U X}$ and $V_{C C}$ under light load conditions of the main power stage, a new structure for the standby converter is proposed as shown in Fig. 2(b). The secondary turns $N_{A U X}$ of the transformer in the conventional structure are divided into $N_{A U X 1}$ and $N_{A U X 2}$ in the proposed structure so that $N_{A U X}=N_{A U X 1}+N_{A U X 2}$. In addition, $V_{A U X}$ can be varied according to the load condition in the main power stage, changing a powering path between the path through $D_{A U X I}$ and the path through $D_{A U X 2}$. It can be achieved by turning on or off the auxiliary PMOS switch $Q_{A U X}$. Moreover, $V_{C C}$ can be varied by turning on or off the NPN transistor $Q_{L R}$. Under heavy load conditions in the main power stage, $Q_{A U X}$ is ON-state so that the powering current can flow through $D_{A U X I}$ and $Q_{A U X}$, and $D_{A U X 2}$ can be reverse bias as shown in Fig. 3(a). Therefore, $V_{A U X}$ is the same as that of the conventional structure as follows: 


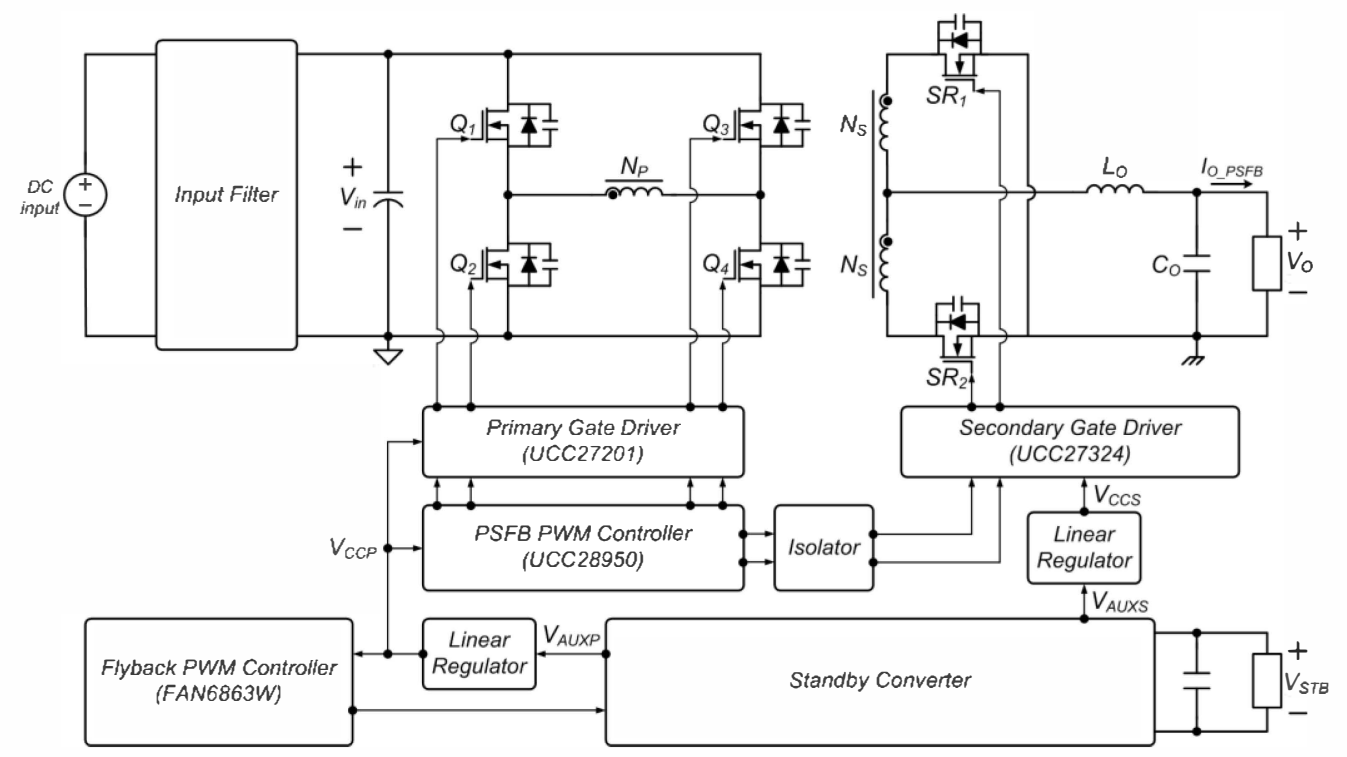

Fig. 4. Typical structure of DC/DC server power supply

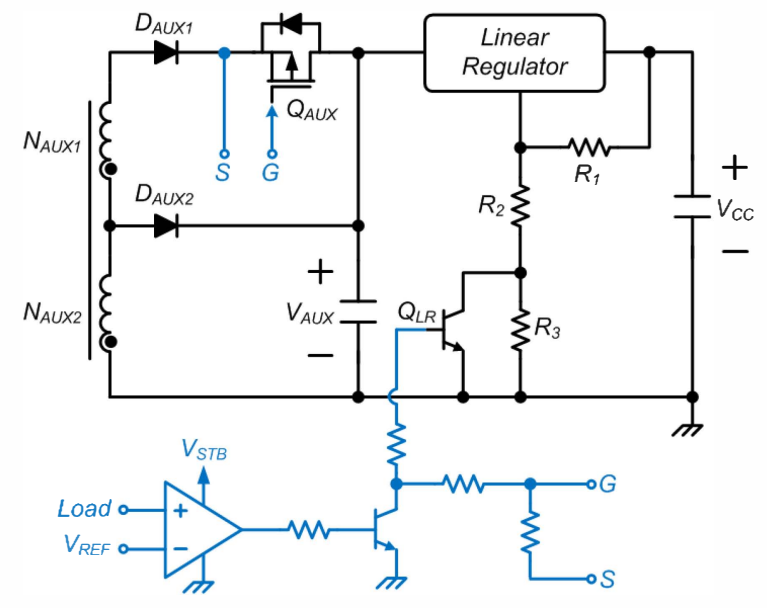

Fig. 5. Control scheme for the proposed method

$$
V_{A U X}=\frac{N_{A U X 1}+N_{A U X 2}}{N_{S}} V_{S T B}=\frac{N_{A U X}}{N_{S}} V_{S T B} .
$$

Furthermore, since $Q_{L R}$ is OFF-state, $V_{C C}$ can be expressed as

$$
V_{C C}=V_{R E F_{-} L R}\left(1+\frac{R_{2}+R_{3}}{R_{1}}\right)
$$

where $V_{R E F L R}$ is the reference voltage in the linear regulator. On the other hand, under light load conditions in the main power stage, $Q_{A U X}$ become OFF-state so that the powering current can flow through $D_{A U X 2}$, and $D_{A U X 1}$ can be turned off as shown in Fig. 3(b). Therefore, $V_{A U X}$ is reduced as follows:

$$
V_{A U X}=\frac{N_{A U X 2}}{N_{S}} V_{S T B} \text {. }
$$

Furthermore, since $Q_{L R}$ is ON-state, $V_{C C}$ is also reduced to the following equation:

$$
V_{C C}=V_{R E F_{-} L R}\left(1+\frac{R_{2}}{R_{1}}\right) \text {. }
$$

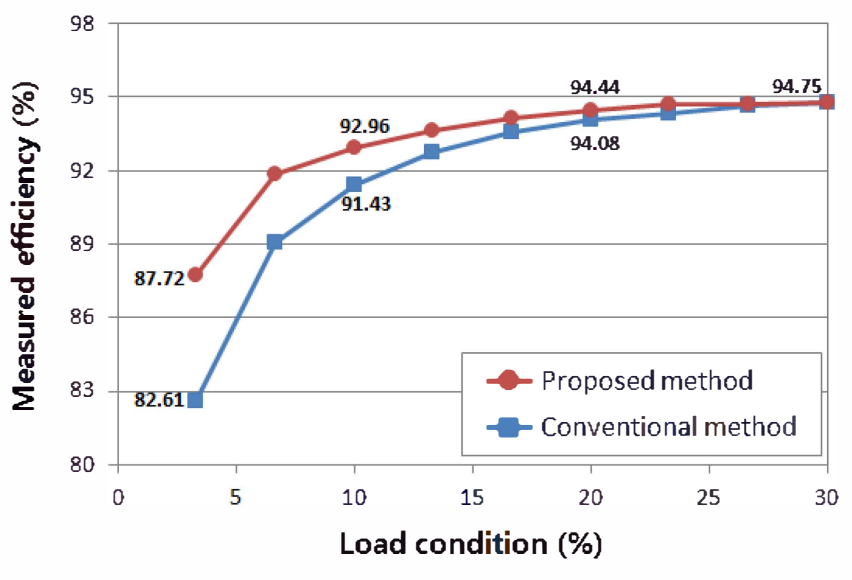

Fig. 6. Measured Efficiency

The proposed standby converter can be effective to improve the light-load efficiency for the power system application with the standby converter such as server computer, PC, LED TV and so on. In addition, the auxiliary winding shown in Fig. 2(b) can be used for the proposed gate driving method in the application without the standby converter where the operating voltage of the controller is served from the auxiliary winding of the main converter.

\section{EXPERIMENTAL RESULTS}

To confirm the validity of the proposed method, $720 \mathrm{~W}$ prototype of the DC/DC server power supply is implemented as shown in Fig. 4. The phase-shift full-bridge (PSFB) converter is adopted for the main power stage, and the multi-output flyback converter shown in Fig. 2(b) is adopted for the standby stage. The parameters of the PSFB converter are the input voltage $V_{i n}=38 \sim 75 \mathrm{~V}$, output voltage $V_{O}=12 \mathrm{~V}$, primary and secondary turns of transformer $N_{P}: N_{S}: N_{S}=5: 2: 2$, magnetizing inductance $L_{m_{-} D C D C}=158 \mu \mathrm{H}$, leakage inductance $L_{\text {lkg } D C D C}=1 \mu \mathrm{H}$, switching 


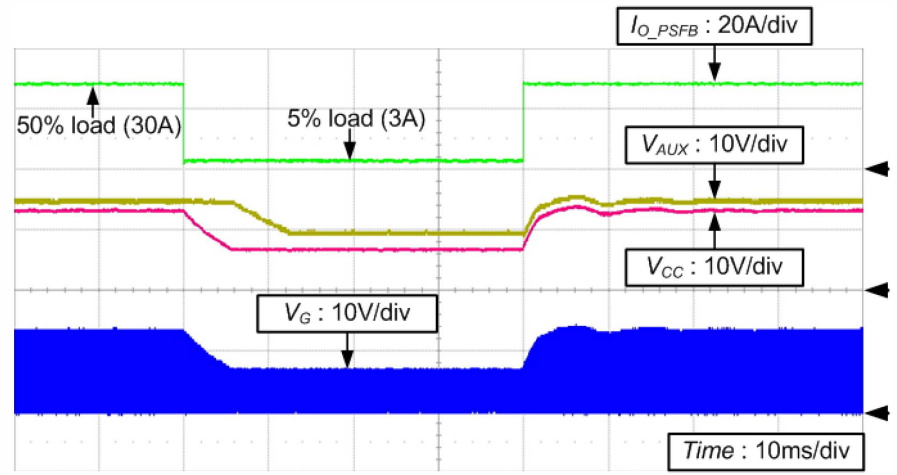

Fig. 7. Experimental waveform of the gate driving voltage according to load change in the main power stage

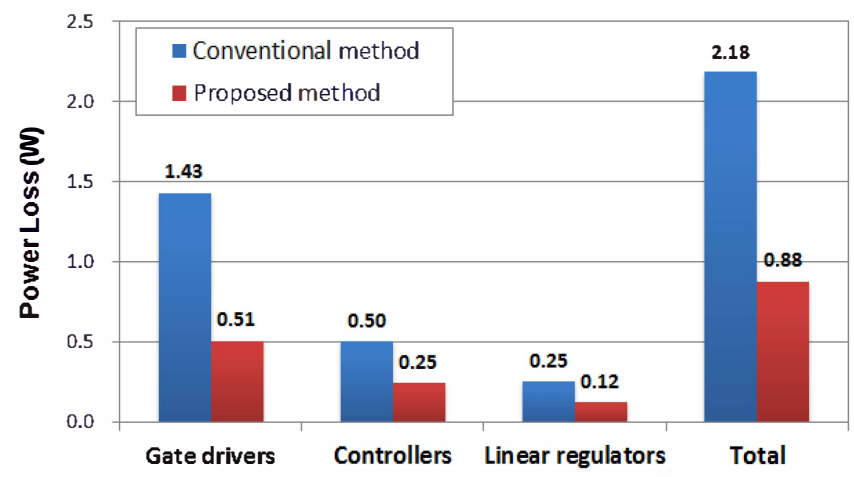

Fig. 8. Loss distribution based on the experimental results under light load conditions

frequency $f_{S_{-} D C D C}=70 \mathrm{kHz}$, primary switches $Q_{I^{\prime}} \sim Q_{f}=$ IPP041N12N, secondary synchronous rectifier $S R_{1} \sim S R_{2}=$ IPP030N10N, output inductor $L_{O}=1 \mu \mathrm{H}$. Meanwhile, the parameters of the flyback converter are the output voltage $V_{S T B}=5 \mathrm{~V}, P_{O}{ }_{S T B}=15 \mathrm{~W}$, primary and secondary turns of transformer $N_{P}: N_{S}=30: 5$, magnetizing inductance $L_{m S T B}=$ $200 \mu \mathrm{H}$, switching frequency $f_{S} S_{T B}=65 \mathrm{kHz}$, primary switch $Q_{S T B}=\mathrm{FQP} 10 \mathrm{~N} 20$, main rectifier diode $D_{S}=\mathrm{SBR} 30 \mathrm{~A} 45 \mathrm{CT}$, auxiliary rectifier diode $D_{A U X 1} \sim D_{A U X 2}=015 \mathrm{MQ} 040 \mathrm{~N}$, auxiliary switch $Q_{A U X}=\mathrm{Si} 4413 \mathrm{DY}$, linear regulator=LM317. In addition, $V_{A U X P}$ and $V_{C C P}$ in the primary side are designed to be $15 \mathrm{~V}$ and $13 \mathrm{~V}$ over $30 \%$ load condition, and to be $10 \mathrm{~V}$ and $8 \mathrm{~V}$ below $30 \%$ load condition, respectively. Thus, $N_{A U X 1}=9, N_{A U X 2}=5$, $R_{l}=1.2 \mathrm{k} \Omega, R_{2}=6.2 \mathrm{k} \Omega$, and $R_{3}=5.1 \mathrm{k} \Omega$ is selected by (4), (5), (6), and (7). In the secondary side, $V_{A U X S}$ and $V_{C C S}$ are designed to be $15 \mathrm{~V}$ and $13 \mathrm{~V}$ over $30 \%$ load condition, and to be $9 \mathrm{~V}$ and $7 \mathrm{~V}$ below $30 \%$ load condition, respectively. Thus, $N_{A U X I}=10$, $N_{A U X 2}=4, R_{I}=1.2 \mathrm{k} \Omega, R_{2}=5.6 \mathrm{k} \Omega$, and $R_{3}=5.6 \mathrm{k} \Omega$ is selected by (4), (5), (6), and (7). In order to turn on or off $Q_{A U X}$ and $Q_{L R}$ depending on the load condition, the control circuit is implemented as shown in Fig. 5. Under heavy load conditions in the main DC/DC power stage, load information is larger than reference voltage $V_{R E F}$, which means that the output of comparator is high and $Q_{A U X}$ is turned on and $Q_{L R}$ is turned off. On the other hand, under light load conditions, the output of comparator is low so that $Q_{A U X}$ is turned off and $Q_{L R}$ is turned on. Fig. 6 shows the measured efficiency for the DC/DC server power supply in Fig. 4 by using the conventional gate driving method where $V_{C C P}=V_{C C S}=13 \mathrm{~V}$ regardless of the load condition and by using the proposed method. It is demonstrated that the efficiency under light load conditions can be improved by using the proposed method. Especially, the efficiency under $10 \%$ load condition is greatly improved. Fig. 7 shows the key waveforms of $V_{C C}, V_{A U X}$ and $V_{G}$ when the output current $I_{O_{-}}$PSFB in the main power stage is changed from $30 \mathrm{~A}$ to $3 \mathrm{~A}$ and vice versa. It is confirmed that the proposed method is operated as expected. Fig. 8 shows the loss distribution calculated by (1), (2), and (3) under light load conditions. As shown in Fig. 8, we can know that the gate driving loss, losses on controller and linear regulator are reduced greatly. Especially, the gate driving loss is significantly reduced because $Q_{G}$ is $128.7 \mathrm{nC}$ for $Q_{I} \sim Q_{+}$ and $113 \mathrm{nC}$ for $S R_{1} \sim S R_{2}$ in the proposed method, whereas $Q_{G}$ is $191.2 \mathrm{nC}$ for $Q_{I} \sim Q_{+}$and $201.4 \mathrm{nC}$ for $S R_{I} \sim S R_{2}$ in the conventional method.

\section{CONCLUSION}

This paper introduces a new load adaptive gate driving method that achieves low power consumption under light load conditions. Compared to the conventional method, the proposed method reduces the gate driving voltage under light load conditions by adjusting the auxiliary output voltage of the standby converter. Therefore, the gate driving loss as well as losses on controller ICs and linear regulator is reduced without the degradation of performance in the main power stage. The validity of this study is confirmed by the experimental results. It is suitable for the power system applications with the standby converter such as server computer, PC, LED TV and so on.

\section{ACKNOWLEDGEMENT}

This work was supported by the National Research Foundation of Korea (NRF) grant funded by the Korea government (MEST) (No.2012-0000981).

\section{REFERENCES}

[1] 80 Plus Program [Online]. Available: http://www.plugloadsolutions.com/ 80 PlusPowerSupplies.aspx

[2] Climate Savers Computing Initiative (CSCI) Web Site [Online]. Available: http://www.climatesaverscomputing.org/

[3] J. K. Kim, S. W. Choi, C. E. Kim, and G. W. Moon, "A New Standby Structure Using Multi-Output Full-Bridge Converter Integrating Flyback Converter," in IEEE Trans. on Industrial Electronics, Vol. 58, No. 10, pp. 4763-4767, Oct. 2011.

[4] S. Y. Cho, I. O. Lee, J. K. Kim, and G. W. Moon, "A New Standby Structure Based on a Forward Converter Integrated With a Phase-Shift Full-Bridge Converter for Server Power Supplies," in IEEE Trans. on Power Electronics, Vol. 28, No. 2, pp. 336-346, Jan. 2013.

[5] J. M. Wang, S. T. Wu, Y. Jiang, and H. J. Chiu, "A dual-mode controller for the boost PFC converter," in IEEE Trans. on Industrial Electronics, Vol. 58, No. 1, pp. 369-372, Jan. 2011.

[6] Y. S. Shin, C. S. Kim, and S. K. Han, "A pulse-frequency-modulated full-bridge DC/DC converter with series boost capacitor," in IEEE Trans. on Industrial Electronics, Vol. 58, No. 11, pp. 5154-5162, Nov. 2011.

[7] Y. Jang, and M. M. Jovanovic, "Light-Load Efficiency Optimization Method," in IEEE Trans. on Power Electronics, Vol. 25, No. 1, pp. 67-74, Jan. 2010.

[8] L. Huber, and M. M. Jovanovic, "Methods of Reducing Audible Noise Caused by Magnetic Components in Variable-Frequency-Controlled Switch-Mode Converters," in IEEE Trans. on Power Electronics, Vol. 26 , No. 6, pp. 1673-1681, Jun. 2011. 
[9] B. Wang, X. Xin, S. Wu, H. Wu, and J. Ying, "Analysis and Implementation of LLC Burst Mode for Light Load Efficiency Improvement," in Applied Power Electronics Conference(APEC'09), pp. $58-64,2009$.

[10] A. Peterchev and S. Sanders, "Digital multimode buck converter control with loss-minimizing synchronous rectifier adaptation," in IEEE Trans. on Power Electronics, Vol. 21, No. 6, pp. 1588-1599, Nov. 2006.

[11] X. Duan, and A. Huang, "Current-mode variable-frequency control architecture for high-current low-voltage dc-dc converters," in IEEE Trans. on Power Electronics, Vol. 21, No. 4, pp. 1133-1137, Jul. 2006.

[12] B-Y. Chen, and Y-S. Lai, "Switching Control Technique of Phase-Shift-Controlled Full-Bridge Converter to Improve Efficiency Under Light-Load and Standby Conditions Without Additional Auxiliary Components," in IEEE Trans. on Power Electronics, Vol. 25, No. 4, pp. 1001-1012, Apr. 2010.

[13] S. Musunuri, and P. L. Chapman, "Improvement of Light-Load Efficiency Using Width-Switching Scheme for CMOS Transistors," in IEEE Power Electronics Letters, Vol. 3, No. 3, pp. 105-110, Sep. 2005.

[14] A. A. Fomani, and W. T. Ng, "A Segmented Gate Driver with Adjustable Driving Capability for Efficiency Optimization," in Proc. Energy Conversion Congress and Exposition(ECCE'10), pp. 2430-2433, Sep. 2010.

[15] A. Parayandeh, and A. Prodic, "Digitally Controlled Low-Power DC-DC Converter with Segmented Output Stage and Gate Charge Based Instantaneous Efficiency Optimization," in Proc. Energy Conversion Congress and Exposition(ECCE'09), pp. 3870-3875, Sep. 2009.

[16] W. Eberle, Y-F. Liu, and P. Sen, "A New Resonant Gate-Drive Circuit With Efficient Energy Recovery and Low Conduction Loss," in IEEE Trans. on Power Electronics, Vol. 55, No. 5, pp. 2213-2221, May. 2008.

[17] Z. Yang, S. Ye, and Y-F. Liu, Z. Du, "A New Dual-Channel Resonant Gate Drive Circuit for Low Gate Drive Loss and Low Switching Loss," in IEEE Trans. on Power Electronics, Vol. 23, No. 3, pp. 1574-1583, May. 2008.

[18] Z. Yang, S. Ye, and Y-F. Liu, "A New Resonant Gate Drive Circuit for Synchronous Buck Converter," in IEEE Trans. on Power Electronics, Vol. 22, No. 4, pp. 1311-1320, Jul. 2007.

[19] H. Fujita, "A Resonant Gate-Drive Circuit Capable of High-Frequency and High-Efficiency Operation," in IEEE Trans. on Power Electronics, Vol. 25, No. 4, pp. 962-969, Apr. 2010.

[20] Y. Chen, F. C. Lee, L. Amoroso, and H-P. Wu, "A Resonant MOSFET Gate Driver With Efficient Energy Recovery," in IEEE Trans. on Power Electronics, Vol. 19, No. 2, pp. 962-969, Mar. 2004.

[21] Q. Li, and P. Wolfs, "The Power Loss Optimization of a Current Fed ZVS Two-Inductor Boost Converter With a Resonant Transition Gate Drive," in IEEE Trans. on Power Electronics, Vol. 21, No. 5, pp. 1253-1263, Sep. 2006.

[22] W. Eberle, Z. Zhang, Y-F. Liu, and P. C. Sen, "A Current Source Gate Driver Achieving Switching Loss Savings and Gate Energy Recovery at 1-MHz," in IEEE Trans. on Power Electronics, Vol. 23, No. 2, pp. 678-691, Mar. 2008.

[23] M. D. Mulligan, B. Broach, and T. H. Lee, "A Constant-Frequency Method for Improving Light-Load Efficiency in Synchronous Buck Converters," in IEEE Power Electronics Letters, Vol. 3, No. 1, pp. 24-29, Mar. 2005.

[24] O. Abdel-Rahman, J. A. Abu-Qahouq, L. Huang, and I. Batarseh, "Analysis and Design of Voltage Regulator With Adaptive Fet Modulation Scheme and Improved Efficiency," in IEEE Trans. on Power Electronics, Vol. 23, No. 2, pp. 896-906, Mar. 2008.

[25] P-J. Liu, and Y-J. E. Chen, "A Self-scailing Gate Drive Technique for Efficiency Improvement of DC-DC Converters," in Proc. International Symposium on industrial Electronics(ISIE'09), pp. 1066-1070, Jul. 2009.

[26] J. A. Abu-Qahouq, W. Al-Hoor, L. yao and I. Batarseh, "Drive Voltage Optimization Controller To Improve Efficiency," in Proc. International Symposium on Circuis and Systems(ISCAS'06), pp. 2277-2280, May. 2006. 